\title{
Flaxseed supplementation improved insulin resistance in obese glucose intolerant people: a randomized crossover design
}

\author{
Yeong Rhee* and Ardith Brunt
}

\begin{abstract}
Background: Obesity leads to an increase in inflammation and insulin resistance. This study determined antioxidant activity of flaxseed and its role in inflammation and insulin resistance in obese glucose intolerant people.

Methods: Using a randomized crossover design, nine obese glucose intolerant people consumed $40 \mathrm{~g}$ ground flaxseed or $40 \mathrm{~g}$ wheat bran daily for 12 weeks with a 4-week washout period. Plasma inflammation biomarkers (CRP, TNF- $\alpha$, and IL-6), glucose, insulin, and thiobaribituric acid reactive substance (TBARS) were measured before and after of each supplementation.

Results: Flaxseed supplementation decreased TBARS $(p=0.0215)$ and HOMA-IR $(p=0.0382)$. Flaxseed or wheat bran supplementation did not change plasma inflammatory biomarkers. A positive relationship was found between TBARS and HOMA-IR ( $r=0.62, p=0.0003)$.

Conclusions: The results of the study weakly support that decreased insulin resistance might have been secondary to antioxidant activity of flaxseed. However, the mechanism(s) of decreased insulin resistance by flaxseed should be further determined using flaxseed lignan.
\end{abstract}

Keywords: flaxseed insulin resistance, oxidative stress, inflammation

\section{Background}

Obesity is a major public health problem [1]. Obesity increases insulin resistance, reactive oxygen species (ROS) generation and nuclear factor (NF)- $\kappa$ B activation $[2,3]$. The increase in NF- $\kappa \mathrm{B}$ activation leads to low grade inflammation and contributes to the development of diabetes [4]. Studies have reported that pro-inflammatory cytokines, tumor necrosis factor (TNF)- $\alpha$ and interleukin (IL)-6, are associated with an increased hepatic C-reactive protein (CRP) synthesis, inflammation, and insulin resistance in humans and animals [5-14]. TNF- $\alpha$ has been positively related to factors associated with metabolic syndrome, including increased triglyceride concentration, blood pressure, and body mass index (BMI) $[5,10]$.

\footnotetext{
* Correspondence: yeong.rhee@ndsu.edu
Department of Health, Nutrition, and Exercise Sciences, North Dakota State

* Correspondence: yeong.rhee@ndsu.edu
Department of Health, Nutrition, and Exercise Sciences, North Dakota State University Fargo, ND 58108-6050, USA
}

(c) 2011 Rhee and Brunt; licensee BioMed Central Ltd. This is an Open Access article distributed under the terms of the Creative Commons Attribution License (http://creativecommons.org/licenses/by/2.0), which permits unrestricted use, distribution, and reproduction in any medium, provided the original work is properly cited.

Antioxidants have been reported to attenuate inflammatory response, insulin resistance, and diabetes development [15-17]. One promising antioxidant is flaxseed. The active ingredient of flaxseed (lignan, secoisolariciresinol diglucoside (SDG)) has significant antioxidant effects by inhibiting DNA scissions and lipid peroxidation and decreaseing ROS [18-21]. Flaxseed also has significant anti-inflammatory effects [22-26]. Flaxseed oil, flaxseed lignan, or flaxseed supplementation significantly decreased serum TNF- $\alpha$, IL-1 $\beta$, IL-6, CRP, glucose, or glycosylated haemoglobin concentrations or increased insulin sensitivity in humans [25-30]. Dietary flaxseed, flaxseed oil, or flaxseed lignan decreased inflammation, oxidative lung damages, lipid peroxidation, or hyperinsulinemia in animals [24,31-33].

Flaxseed is safe and readily available for dietary consumption that positively affects inflammation, glycemic control, and oxidative stress. The current study was conducted to determine the mechanism(s) by which 
flaxseed offers the protection against insulin resistance and inflammation via regulation of oxidative stress. It was hypothesized that flaxseed supplementation will decrease oxidative stress, thus reducing inflammation biomarkers and insulin resistance. The effects of flaxseed on oxidative stress, insulin resistance, and inflammation were reported in this article.

\section{Methods}

The present study was approved by the Institutional Review Board at North Dakota State University. Written consent was obtained from all participants before the initiation of the study.

\section{Participant Selection}

Potential participants who were overweight, hypertensive, and with a family history of diabetes were screened for impaired fasting plasma glucose. Following a positive impaired fasting plasma glucose $(>100 \mathrm{mg} / \mathrm{dL})$, an oral glucose tolerance test (OGTT) was completed. Individuals included into the study had fasting plasma glucose concentration between $100-125 \mathrm{mg} / \mathrm{dL}$, and following a $100 \mathrm{~g}$ oral glucose load, had 2-hour plasma glucose of greater than $140 \mathrm{mg} / \mathrm{dL}$ but less than $199 \mathrm{mg} / \mathrm{dL}$. The dose of $100 \mathrm{~g}$ oral glucose was used following current diagnostic test guidelines of Sanford Health Laboratory in consideration of obesity and increased body surface area to be covered by glucose solution [34]. General health status including vitamin/mineral/herbal supplementation and medication intake was determined by health questionnaires before and at the end of the study. Individuals excluded from the study included: people (1) on prescribed oral hypoglycemic medication or insulin injection; (2) had any diagnosed illness other than controlled hypertension or impaired glucose tolerance; or (3) allergic to either flaxseed or wheat. Thirty three people were screened and 11 qualified for study participation.

\section{Design and Treatments}

A randomized crossover research design was used for the study. Eleven participants were randomly assigned into one of two groups: flaxseed or wheat bran supplementation group. Participants received a daily allotment of either $40 \mathrm{~g}$ of wheat bran or flaxseed in form of ground grain or bread for 12 weeks. Participants were instructed to incorporate the supplement in their daily meals using a method of their choice. Following a 4week washout period of no supplements, participants received the alternate supplement (either flaxseed or wheat bran) for another 12 weeks. The ingredients in the bread were adjusted to provide similar calories in both supplemental breads. The bread was baked at a local bakery. Before entering the study, participants were instructed to substitute the study supplement for some of their usual carbohydrate and fat consumed at the meal so that no additional calories would be consumed. Participants were requested to keep the supplement in the freezer to maintain freshness. Participants were also asked to record the amount eaten and to return leftover supplements to the investigators. The collected leftover supplements were weighed by the investigators to check dietary compliance. Nutrient compositions of wheat bran bread or flaxseed bread were analyzed using Food Processor software (version 10.5.1, ESHA Research, Salem, OR).

A health questionnaire that included birth date, current health conditions, medication use, vitamin, mineral, or herbal supplement use, and exercise practices was completed at the screening. A follow-up health questionnaire was completed at the end of the study to determine if any changes had occurred in the participant's health or exercise practices. Each participant's height (without shoes) was measured during the screening test. Using a balance beam scale, each participant was weighed at the screening, at the beginning and end of each supplementation. BMI was calculated using the equation BMI $=$ weight $(\mathrm{kg}) /$ height $^{2}\left(\mathrm{~m}^{2}\right)$. Waist circumference was measured using a measuring tape. The measuring tape was placed around the abdomen at the level of the iliac crest and took the reading at the end of a normal expiration [35]. The Block Brief 2000 Food Questionnaire, a validated self-administered 66-item semi-quantitative food frequency questionnaire [36], was administered at the beginning of each supplementation.

\section{Blood Sample Collection and Laboratory Assays}

After a 12-hour fast, participants had venous blood drawn. Samples were collected before and after each 12week supplementation. Fasting plasma glucose concentration was measured by Sanford Health; the result was reported elsewhere [37]. Plasma insulin concentration was measured using an enzyme-linked immunosorbent assay (ELISA) kit (Alpco Co., Salem, NH). Plasma TNF$\alpha$ (Invitrogen, Carlsbad, CA), IL-6 (Cayman Chemical, Ann Arbor, MI), and high sensitivity (hs)-CRP (BioCheck, Inc., Burlingame, CA) concentrations were measured using ELISA kits. Thiobaribituric acid reactive substance (TBARS) was measured to estimate oxidative stress using a kit (ZeptoMetrix Co, Buffalo, NY). Homeostasis model assessment (HOMA-IR) was used to estimate insulin resistance. The following formula was used for HOMA-IR calculation: (insulin $[\mathrm{pmol} / \mathrm{L}] \times$ glucose $[\mathrm{mmol} / \mathrm{L}] / 22.5)[38]$.

\section{Statistical Analysis}

SAS software (version 9.1; SAS, Cary, NC) was used for data analysis. Data were tested for normality by a 
univariate test and homogeneity of variances by a t-test. The effect of treatment groups (between wheat bran and flaxseed groups) on plasma insulin, HOMA-IR, TBARS, TNF- $\alpha$, IL-6, and hs-CRP concentrations was assessed using two sample t-tests whereas the effect of the 12 weeks of supplementation (within each supplementation group) on plasma insulin, HOMA-IR, TBARS, TNF- $\alpha$, IL-6, and hs-CRP concentrations was assessed using paired t-tests. Pearson correlation coefficients were used to assess relationships among the test variables. A type I error rate of 0.05 was used to assess significance for all statistical tests.

\section{Results}

A total of eleven people initially participated in the study. Four participants dropped out: two after first blood sample collection and another two after the third blood sample collection. The first two participants withdrew from the study due to personal reasons unrelated to the study; the latter two participants dropped out of the study because they did not like the wheat bran supplement. The two who dropped out during the first phase of supplementation were excluded from the data analysis; however, the participants who dropped out during the second phase of supplementation were included in the data analysis. The overall compliance rate with dietary supplements was $>95 \%$. Supplemental bread that contained $40 \mathrm{~g}$ of either ground flaxseed or wheat bran, provided $453 \mathrm{kcal}$ and $398 \mathrm{kcal}$, respectively [37]. Table 1 shows the nutrient composition of supplemental bread.

The average age of the participants was $54.7 \pm 6.6$ years. Of the nine participants, four were male and five were female. Participants reported no change in dietary intake, health status including inflammatory status, or exercise habits throughout the study. All participants

Table 1 Composition of daily supplemental flaxseed bread and wheat bran bread*

\begin{tabular}{lcc}
\hline Measures & Flaxseed & Wheat bran \\
\hline Energy $(\mathrm{kcal} / \mathrm{d})$ & 453 & 398 \\
Carbohydrate $(\mathrm{g} / \mathrm{d})$ & 72.2 & 83.4 \\
Fiber $(\mathrm{g} / \mathrm{d})$ & 13.1 & 18.6 \\
Protein (g/d) & 16.8 & 14.8 \\
Fat (g/d) & 16.4 & 6.0 \\
Saturated fatty acids (g/d) & 6.6 & 0.8 \\
Monounsaturated fatty acids (g/d) & 4.5 & 1.3 \\
Polyunsaturated fatty acids (g/d) & 5.0 & 3.2 \\
Omega 3 fatty acid (g/d) & 8.4 & 0.1 \\
Omega 6 fatty acid (g/d) & 2.5 & 2.9 \\
\hline
\end{tabular}

*Composition of flaxseed and wheat bran bread was reported previously [37]. Composition of daily supplemental flaxseed bread and wheat bran bread are based on ingredient analysis using Food Processor Software (version 10.5.1, ESHA Research, Salem, OR). were nonsmokers and reported exercising for $30 \mathrm{~min}$ utes or more per day, 3-5 days per week. Six participants reported taking multivitamins; two participants reported taking calcium/magnesium supplements; and one participant reported taking a vitamin E supplement.

Body weight and BMI were not significantly different compared to the baseline, nor between treatment groups. The average body weight was $96.2 \pm 18.9$ vs. $92.2 \pm 20.4(\mathrm{~kg})$, flaxseed group; $94.7 \pm 20.0$ vs. $95.2 \pm$ $20.3(\mathrm{~kg})$, wheat bran group at the baseline and end of the study, respectively. The average BMI was $32.4 \pm 8.2$ vs. $30.3 \pm 5.5\left(\mathrm{~kg} / \mathrm{m}^{2}\right)$, flaxseed group; $32.0 \pm 8.3$ vs. 32.4 $\pm 8.3\left(\mathrm{~kg} / \mathrm{m}^{2}\right)$, wheat bran group at the baseline and end of the study, respectively. No significant relationships between weight change and glucose, insulin, HOMA-IR, or inflammatory biomarkers were found. The waist circumference did not change significantly. The average waist circumference was $106.9 \pm 13.5$ vs. $105.9 \pm 12.7$ $(\mathrm{cm})$, flaxseed group; $108.7 \pm 12.2$ vs. $106.7 \pm 13.5(\mathrm{~cm})$, wheat bran group at the baseline and end of the study, respectively.

Based on a self-administered 66-item semi-quantitative food frequency questionnaire, no significant differences were observed in mean daily energy and nutrient intakes between each supplementation. At the beginning of the first supplementation, mean energy intake was $1875 \pm$ $798 \mathrm{kcal} / \mathrm{d}$, with $17 \%, 38 \%$, and $45 \%$ coming from protein, fat and carbohydrates, respectively. At the beginning of the second supplementation, mean energy intake was $2038 \pm 973 \mathrm{kcal} / \mathrm{d}$, with $17 \%$, 37\%, and $46 \%$ coming from protein, fat and carbohydrates, respectively. Vitamins $\mathrm{C}$ and $\mathrm{E}$ and beta carotene, antioxidants, consumed as food were not significantly different among the participants. Software limitations prevented analysis of the dietary intake of $\alpha$-linolenic acid and insoluble and soluble fiber.

Flaxseed supplementation significantly reduced fasting plasma glucose concentration compared to the baseline ( $0 \mathrm{wk}$ ) and compared to the wheat bran supplementation: $5.92 \pm 0.31$ vs $4.79 \pm 0.17(\mathrm{mmol} / \mathrm{L})$, flaxseed group; 5.67 \pm 0.14 vs. $5.73 \pm 0.35(\mathrm{mmol} / \mathrm{L})$, wheat bran group [37] Flaxseed supplementation did not significantly change fasting plasma insulin concentration (Figure 1). However, 12 weeks of wheat bran supplementation significantly reduced plasma insulin concentration compared to baseline $(\mathrm{p}=0.026$, Figure 1$)$.

When estimating insulin resistance using HOMA-IR [38], flaxseed supplementation significantly decreased an HOMA-IR index (34.7\%) compared to the baseline. Wheat bran supplementation did not significantly change an HOMA-IR index (Figure 2). Moreover, flaxseed supplementation decreased plasma TBARS concentration compared to baseline (Figure 3). Significant relationships were found between HOMA-IR and insulin 


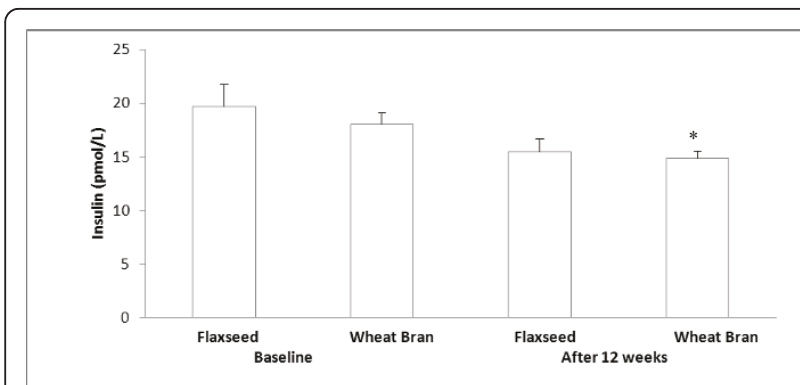

Figure 1 Fasting plasma insulin concentrations before and after each supplementation. Data are presented as mean \pm standard error, $n=7-9$; Statistical significance level was set at 0.05 . *Significantly decreased after 12 weeks of wheat bran supplementation compared to the baseline, $p=0.026$. No significant change in plasma insulin concentration after 12 weeks of flaxseed supplementation. No significant differences in plasma insulin concentration between flaxseed and wheat bran supplementation groups

$(\mathrm{r}=0.89, \mathrm{p}<0.0001)$ and HOMA-IR and glucose $(\mathrm{r}=$ $0.66, \mathrm{p}<0.0001)$.

The inflammation biomarkers, TNF- $\alpha$, IL- 6 , and hs-CRP did not change significantly following 12 weeks of flaxseed or wheat bran supplementation (Table 2). However, positive relationships between plasma glucose and TBRAS $(\mathrm{r}=0.39, \mathrm{p}=0.034)$, TBARS and TNF $-\alpha(\mathrm{r}=0.57, \mathrm{p}=$ $0.0011)$, TBARS and insulin $(r=0.52, p=0.0035)$, and TBARS and HOMA-IR $(r=0.62, p=0.0003)$ were found.

\section{Discussion}

The current study was intended to determine, if the flaxseed supplementation would have an effect on insulin resistance via regulation of oxidative stress in obese glucose intolerant people. The current study found that flaxseed supplementation decreased insulin resistance. Although the plasma insulin concentration did not change significantly, an HOMA-IR index significantly

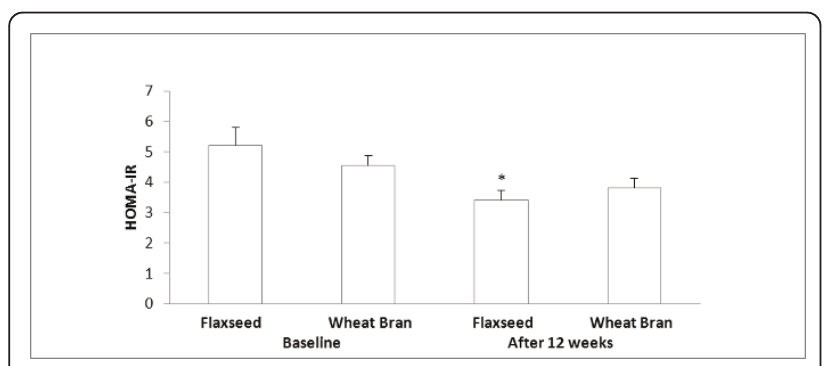

Figure 2 HOMA-IR index before and after each supplementation Data are presented as mean \pm standard error, $n=7-9$; Statistical significance level was set at 0.05. *Significantly decreased after 12 weeks of flaxseed supplementation compared to the baseline, $\mathrm{p}=$ 0.0382. No significant change in HOMA-IR after 12 weeks of wheat bran supplementation. No significant differences in HOMA-IR between flaxseed and wheat bran supplementation groups

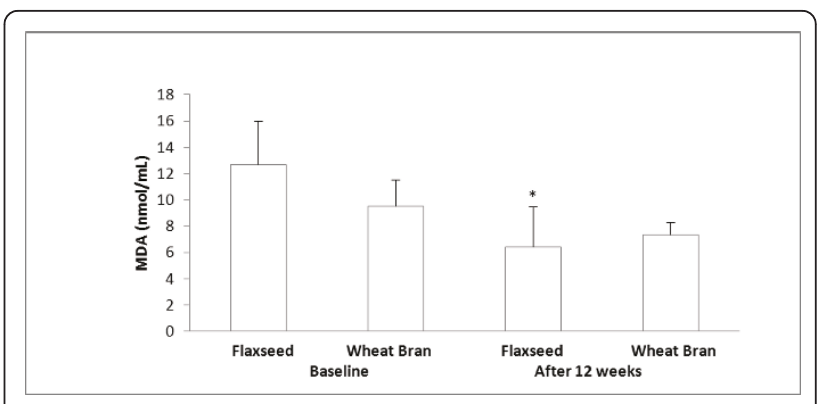

Figure 3 Plasma TBARS concentrations before and after each supplementation ${ }^{1}$. ${ }^{1}$ TBARS is an indicator for lipid peroxidation, and it is measured in MDA equivalents. Data are presented as mean \pm standard error, $n=7-9$; Statistical significance level was set at 0.05. *Significantly decreased after 12 weeks of flaxseed supplementation compared to the baseline, $p=0.0215$. No significant change in plasma TBARS concentration after 12 weeks of wheat bran supplementation. No significant differences in plasma TBARS concentration between flaxseed and wheat bran supplementation groups

decreased, suggesting a decrease in insulin resistance or decreased glucose concentration following flaxseed supplementation. A highly significant positive relationship $(\mathrm{r}=0.89)$ between HOMA-IR and insulin indicates that the decreased HOMA-IR is more closely related to insulin concentration than glucose concentration. Decreased HOMA-IR following flaxseed lignan or flaxseed supplementation without significant changes in insulin concentration has also been reported by others $[28,30]$. No significant changes in plasma insulin concentration following flaxseed supplementation might be related to small sample sizes in the current study which warrant the need of future study with a larger sample size.

In the present study, flaxseed supplementation showed a beneficial effect on oxidative stress as determined by TBARS. Flaxseed supplementation significantly decreased TBARS concentration which suggests decreased lipid peroxidation in these participants and an antioxidant activity of flaxseed.

In the present study, TNF- $\alpha$, IL-6, and CRP remained within normal ranges. The results suggest that these

Table 2 Inflammation biomarker changes over the course of the experiment ${ }^{1}$

\begin{tabular}{lcccc}
\hline & \multicolumn{2}{c}{ Baseline } & \multicolumn{2}{c}{ After 12 weeks } \\
\cline { 2 - 5 } & Flaxseed & Wheat Bran & Flaxseed & Wheat Bran \\
\hline IL-6 $(\mathrm{pg} / \mathrm{mL})$ & $3.2 \pm 0.6$ & $3.1 \pm 0.5$ & $3.2 \pm 0.5$ & $3.6 \pm 0.8$ \\
TNF- $\alpha(\mathrm{pg} / \mathrm{mL})$ & $0.9 \pm 0.4$ & $0.6 \pm 0.5$ & $0.8 \pm 0.5$ & $0.7 \pm 0.6$ \\
$\mathrm{hs}-\mathrm{CRP}(\mathrm{mg} / \mathrm{L})$ & $3.6 \pm 1.7$ & $4.6 \pm 2.1$ & $3.9 \pm 0.9$ & $7.2 \pm 5.5$ \\
\hline
\end{tabular}

${ }^{1}$ All values are mean \pm standard deviation; $n=7-9$; Statistical significance level was set at 0.05

The inflammation biomarkers, IL-6, TNF- $\alpha$, and hs-CRP did not change significantly following 12 weeks of flaxseed or wheat bran supplementation. No significant difference in IL-6, TNF- $\alpha$, and hs-CRP between flaxseed and wheat bran supplementation groups 
obese participants did not have low grade systemic inflammation, but these participants are classified as a high cardiovascular disease risk group [39]. Studies show that CRP concentration remained the same following flaxseed or flaxseed lignan supplementation while CRP concentration in the control supplementation group increased $[29,30,40,41]$. A similar result was found in the present study. While CRP concentration in flaxseed supplementation group remained the same as the baseline, it increased following wheat bran (control) supplementation. Although flaxseed oil has been reported to significantly decrease serum TNF- $\alpha$ or IL- 6 in humans $[25,26]$, no significant changes were found in TNF- $\alpha$ or IL- 6 following flaxseed or flaxseed lignan supplementation $[28-30,40]$ which is in agreement with the findings of the present study.

Increased glucose oxidation and NADPH oxidase activity secondary to hyperglycemia and obesity increase ROS generation $[42,43]$. Participants in the present study were hyperglycemic and obese, and they had normal TNF- $\alpha$ and IL- 6 concentrations which suggest that the participants might have had increased oxidative stress secondary to high plasma glucose concentrations and their obesity not secondary to inflammation. Increased oxidative stress may suppress insulin receptor activation or decrease the translocation of GLUT4 on the cell membrane [44]. It was found that antioxidants increase glucose disposal via increased translocation of GLUT 4 on the cell membrane and increase basal glucose uptake via redistribution of GLUT $1[44,45]$. Although GLUT expression or cellular glucose uptake was not measured in the present study, SDG treatment increased basal glucose uptake in human RBCs in our previous study [46].

Increased ROS, especially hydroxyl radicals increase TBARS concentration. TBARS is an indicator for lipid peroxidation, and it is measured in malondialdehyde (MDA) equivalents. Decreased TBARS concentration following flaxseed supplementation indicates decreased lipid peroxidation. SDG in flaxseed decreases lipid peroxidation by scavenging hydroxyl radical $[47,48]$. Reduced lipid peroxidation may have maintained cell membrane integrity keeping insulin receptor intact, thus may have contributed to increased glucose disposal. The positive relationships seen between TBARS and insulin and TBARS and HOMA-IR in the present study are in agreement with other study findings that increased ROS triggers insulin resistance [49-52].

Weight loss improves insulin resistance by increasing insulin sensitivity [53]. However, no significant weight changes in these participants suggest that decreased HOMA-IR index is not related to weight loss. Our results support that high glucose concentrations increase oxidative stress [54] as shown increased TBARS. As seen by others [51] the positive relationships between TBARS and HOMA-IR indicate that increased oxidative stress may have increased insulin resistance in these obese participants. Moreover, positive relationships between TBARS and TNF- $\alpha$ concentrations found in this study support that increased oxidative stress increases pro-inflammatory cytokines [55].

Soluble and insoluble fiber in flaxseed shown to improve glycemic control [56], and is inversely related to CRP concentrations [57]. The current study did not evaluate the fiber effects on the insulin resistance and inflammation biomarkers. However, as discussed in elsewhere [37], the wheat bran supplementation provided higher concentration of dietary fiber $(18.6 \mathrm{~g} / \mathrm{d})$ compared to flaxseed $(13.1 \mathrm{~g} / \mathrm{d})$ in the current study. In addition, daily dietary fiber intake was not different between flaxseed and wheat bran groups [37]. No significant changes in inflammation biomarkers or insulin resistance indicators (glucose or HOMA-IR) following wheat bran supplementation indicate that the antioxidant activity of flaxseed or other bioactive component of flaxseed such as $\alpha$-liniolenic acid might have attributed to decreased insulin resistance rather than dietary fiber.

Decreased insulin resistance might be attributed to lignan via its antioxidant activity of flaxseed in these obese participants. However, the present study was not able to identify the direct role of lignan in insulin resistance due to a high $\alpha$-linolenic acid content in whole flaxseed. Therefore, further study is needed to determine the effects of flaxseed lignan on insulin resistance and peripheral glucose uptake to identify the mechanism(s) of decreased insulin resistance. Although flaxseed decreased HOMA-IR and TBARS, but none of the changes in TBARS, insulin, and HOMA-IR between flaxseed and wheat bran supplementation groups was significantly different. No significant difference in HOMA-IR, insulin, and TBARS between flaxseed and wheat bran supplementation also supports the need of study using flaxseed lignan to further determine the mechanism(s) of decreased insulin resistance via antioxidant activity of flaxseed.

The present results indicate that obese participants were glucose intolerant without low grade systemic inflammation. Since these participants did not have an identified inflammatory condition, flaxseed supplementation may have not affected these inflammation biomarkers. If these participants had systemic inflammation secondary to obesity or impaired glucose tolerance, flaxseed effects on inflammation may have been seen. This also suggests the need of future study using either animal models with inflammation or people with systemic inflammation to determine flaxseed effects on inflammation. 


\section{Conclusions}

In conclusion, it was hypothesized that an antioxidant (lignan) in flaxseed would decrease ROS generation which downregulates TNF- $\alpha$ and IL- 6 production. Therefore, the bioactive component of flaxseed, lignan, would decrease inflammation and insulin resistance. Although no statistical differences were seen in inflammation biomarkers following flaxseed supplementation, the positive relationship between TBARS and TNF- $\alpha$ suggests that increased oxidative stress would increase TNF- $\alpha$. Moreover, the positive relationship between TBARS and HOMA-IR suggests that increased oxidative stress increased insulin resistance. Although flaxseed supplementation decreased HOMA-IR and TBRAS independently, these variables were not significantly different compared to wheat bran supplementation. No significant difference in HOMA-IR and TABRS between flaxseed and wheat bran supplementation groups weakly supports a hypothesis of the current study: flaxseed supplementation will decrease oxidative stress, thus reducing inflammation biomarkers and insulin resistance. A small sample size and a cumulative effect of $\alpha$-linolenic acid and/or fiber in the flaxseed might have caused nonsignificant differences in HOMA-IR and TBARS between flaxseed and wheat bran supplementation groups. Therefore, further study is needed to determine the role of antioxidant activity of flaxseed in insulin resistance using flaxseed lignan and with a larger sample size.

\section{List of abbreviations used}

BMl: body mass index; ELISA: enzyme-linked immunosorbent assays; HOMA IR: homeostasis model assessment-insulin resistance; hs-CRP: high sensitivity C-reactive protein; IL: interleukin; MDA: malondialdehyde; NF: nuclear factor; ROS: reactive oxygen species; SDG: secoisolariciresinol diglucoside; TBARS: thiobaribituric acid reactive substance; TNF: tumor necrosis factor

\section{Acknowledgements}

This study was supported by grants from North Dakota State University Research Development Support Program and North Dakota Oilseed Council. The authors thank volunteers for participating in the study, and Curt Doetkott for aiding in statistical analyses. The authors express special thanks to Dr. Jack Carter, emeritus professor at North Dakota State University, for providing his expertise in flaxseed, acquiring flaxseed and durum wheat bran, and arranging proximate and lignan analyses for the study. The authors also like to acknowledge North Dakota Oilseed (flaxseed) Council, Bismark, ND, for provision of ground full-fat yellow omega flaxseed and Dakota Growers Pasta Co., Carrington, ND, for provision of durum wheat bran throughout the study. The authors also thank Professor Gregory Gass for critical review of the manuscript. The authors thank the North Dakota State University College of Human Development and Education and the Department of Health, Nutrition, and Exercise Sciences for the print charge support.

\section{Authors' contributions}

YR participated in the design of the study, performed the sample and data analyses, and drafted the manuscript. $A B$ participated in the design of the study and helped draft the manuscript. All authors read and approved the final manuscript.

\section{Competing interests}

The authors declare that they have no competing interests.

Received: 9 December 2010 Accepted: 9 May 2011

Published: 9 May 2011

\section{References}

1. Flegal KM, Carroll MD, Ogden $C L$, Curtin LR: Prevalence and trends in obesity among US adults, 1999-2008. JAMA 2010, 303:235-241.

2. Felber J, Golay A: Pathways from obesity to diabetes. Int J Obes 2002, 26: S39-S45

3. Grundy S, Cleeman J, Daniels S, Donato K, Eckel R, Franklin B, Gordon D, Krauss R, Savage P, Smith S, Spertus J, Costa F: Diagnosis and management of the metabolic syndrome: an American Heart Association/National Heart, Lung, and Blood Institute scientific statement. Circulation 2005, 112:e285-e290.

4. Zozulinska D, Wierusz-Wysocka B: Type 2 diabetes mellitus as inflammatory disease. Diabetes Res Clin Pract 2005, 74:S12-S16.

5. Moon Y, Kim D, Song D: Serum tumor necrosis factor-a levels and components of the metabolic syndrome in obese adolescents. Metabolism 2004, 53:863-867.

6. Hotamisligil G, Shargill N, Spiegelman B: Adipose expression of tumor necrosis factor-alpha: direct role in obesity-linked insulin resistance. Science 1993, 259:87-91.

7. Uysal K, Wiesbrock S, Marino M, Hotamisligil G: Protection from obesityinduced insulin resistance in mice lacking TNF-alpha function. Nature 1997, 389:610-614.

8. Klover P, Zimmers T, Koniaris L, Mooney R: Chronic exposure to interleukin-6 causes hepatic insulin resistance in mice. Diabetes 2003, 52:2784-2789.

9. Senn J, Klover P, Nowak I, Mooney R: Interleukin-6 induces cellular insulin resistance in hepatocytes. Diabetes 2002, 51:3391-3399.

10. Kern P, Ranganathan S, Li C, Wood L, Ranganathan G: Adipose tissue tumor necrosis factor and interleukin- 6 expression in human obesity and insulin resistance. Am J Physiol Endocrinol Metab 2001, 280:E745-751.

11. Hotamisligil G, Budavari A, Murray D, Spiegelman B: Reduced tyrosine kinase activity of the insulin receptor in obesity-diabetes. Central role of tumor necrosis factor-a. J Clin Invest 1994, 94:1543-1549.

12. Hotamisligil G: Mechanisms of TNF-a induced insulin resistance. Exp Clin Endocrinol Diabetes 1999, 107:119-125.

13. Xu H, Barnes G, Yang Q, Tan G, Yang D, Chou C, Sole J, Nichols A, Ross J, Tartaglia L, Chen $\mathrm{H}$ : Chronic inflammation in fat plays a crucial role in the development of obesity-related insulin resistance. J Clin Invest 2003, 112:1821-1830.

14. Puglisi $M$, Fernandez $M$ : Modulation of C-reactive protein, tumor necrosis factor-alpha, and adiponectin by diet, exercise, and weight loss. J Nutr 2008, 138:2293-2296.

15. Chun O, Chung S, Claycombe K, Song W: Serum C-reactive protein concentrations are inversely associated with dietary flavonoid intake in U.S. adults. J Nutr 2008, 138:753-760.

16. Bitar M, Al-Saleh E, Al-Mulla F: Oxidative stress-mediated alterations in glucose dynamics in a genetic animal model of type II diabetes. Life Sci 2005, 77:2552-2573.

17. Vinayaga-Moorthi R, Bobby Z, Selvaraj N, Sridhar M: Vitamin E protects the insulin sensitivity and redox balance in rat L6 muscle cells exposed to oxidative stress. Clin Chim Acta 2006, 367:132-136.

18. Prasad K: Antioxidant activity of secoisolariciresinol diglucoside-derived metabolites, secoisolariciresinol, enterodiol, and enterolactone. Int J Angiol 2000, 9:220-225.

19. Kitts D, Yuan Y, Wijewickreme A, Thompson L: Antioxidant activity of the flaxseed lignan secoisolariciresinol diglucoside and its mammalian lignan metabolites enterodiol and enterolactone. Mol Cell Biochem 1999, 202:91-100.

20. Newairy A, Abdou H: Protective role of flax lignans against lead acetate induced oxidative damage and hyperlipidemia in rats. Food Chem Toxicol 2009, 47:813-818.

21. Lee J, Bhora F, Sun J, Cheng G, Arguiri E, Solomides C, Chatterjee S, Christofidou-Solomidou M: Dietary flaxseed enhances antioxidant defenses and is protective in a mouse model of lung ischemiareperfusion injury. Am J Physiol Lung Cell Mol Physiol 2008, 294:L255-265. 
22. Cohen S, Moore A, Ward W: Flaxseed oil and inflammation-associated bone abnormalities in interleukin-10 knockout mice. J Nutr Biochem 2005, 16:368-374.

23. Dupasquier C, Dibrov E, Kneesh A, Cheung P, Lee K, Alexander $H$, Yeganeh B, Moghadasian M, Pierce G: Dietary flaxseed inhibits atherosclerosis in the LDL receptor-deficient mouse in part through antiproliferative and anti-inflammatory actions. Am J Physiol Heart Circ Physiol 2007, 293:H2394-2402.

24. Ogborn M, Nitschmann E, Bankovic-Calic N, Weiler H, Aukema H: Effects of flaxseed derivatives in experimental polycystic kidney disease vary with animal gender. Lipids 2006, 41:1141-1149.

25. Caughey G, Mantzioris E, Gibson R, Cleland L, James M: The effect on human tumor necrosis factor alpha and interleukin 1 beta production of diets enriched in $\mathrm{n}-3$ fatty acids from vegetable oil or fish oil. Am J Clin Nutr 1996, 63:116-122.

26. Paschos G, Yiannakouris N, Rallidis L, Davies I, Griffin B, Panagiotakos D, Skopouli F, Votteas $V$, Zampelas A: Apolipoprotein E genotype in dyslipidemic patients and response of blood lipids and inflammatory markers to alpha-linolenic acid. Angiology 2005, 56:49-60.

27. Zhang W, Wang X, Liu Y, Tian H, Flickinger B, Empie M, Sun S: Dietary flaxseed lignan extract lowers plasma cholesterol and glucose concentrations in hypercholesterolaemic subjects. Br J Nutr 2008 99:1301-1309.

28. Pan A, Sun J, Chen Y, Ye X, Li H, Yu Z, Wang Y, Gu W, Zhang X, Chen X, Demark-Wahnefried W, Liu Y, Lin X: Effects of a flaxseed-derived lignan supplement in type 2 diabetic patients: a randomized, double-blind, cross-over trial. PLoS One 2007, 2:e1148.

29. Hallund J, Tetens I, Bügel S, Tholstrup T, Bruun J: The effect of a lignan complex isolated from flaxseed on inflammation markers in healthy postmenopausal women. Nutr Metab Cardiovasc Dis 2008, 18:497-502.

30. Bloedon L, Balikai S, Chittams J, Cunnane S, Berlin J, Rader D, Szapary P. Flaxseed and cardiovascular risk factors: results from a double blind, randomized, controlled clinical trial. J Am Coll Nutr 2008, 27:65-74.

31. Lee J, Krochak R, Blouin A, Kanterakis S, Chatterjee S, Arguiri E, Vachani A, Solomides C, Cengel K, Christofidou-Solomidou M: Dietary flaxseed prevents radiation-induced oxidative lung damage, inflammation and fibrosis in a mouse model of thoracic radiation injury. Cancer Biol Ther 2009, 8:47-53.

32. Velasquez M, Bhathena S, Ranich T, Schwartz A, Kardon D, Ali A, Haudenschild C, Hansen C: Dietary flaxseed meal reduces proteinuria and ameliorates nephropathy in an animal model of type II diabetes mellitus. Kidney Int 2003, 64:2100-2107.

33. Fukumitsu S, Aida K, Ueno N, Ozawa S, Takahashi Y, Kobori M: Flaxseed lignan attenuates high-fat diet-induced fat accumulation and induces adiponectin expression in mice. Br J Nutr 2008, 100:669-676.

34. Oral Glucose Tolerance Test. [http://www.sanfordhealth.org/ Healthlnformation/HealthWise/Topic/hw44896\#hw44914].

35. Lee R, Nieman D: Body fat distribution. In Nutritional Assessment.. 3 edition. Edited by: Meyers LM. New Yoir: McGarw-Hill; 2003:182-183.

36. Nutrition Quest Assessment Tools and Analysis Services. [http://www. nutritionquest.com/assessment/].

37. Rhee $Y$, Brunt $A$ : Flaxseed supplementation was effective in lowering serum glucose and triacylglycerol in glucose intolerant people. JANA 2006, 9:28-34

38. Mericq V, Ong K, Bazaes R, Peña V, Avila A, Salazar T, Soto N, Iñiguez G, Dunger $D$ : Longitudinal changes in insulin sensitivity and secretion from birth to age three years in small- and appropriate-for-gestational-age children. Diabetologia 2005, 48:2609-2614.

39. Pearson $T$, Mensah $G$, Alexander $R$, Anderson J, Cannon $R$, Criqui M, Fadl $Y$, Fortmann S, Hong Y, Myers G, Rifai N, Smith S, Taubert K, Tracy R, Vinicor F: Markers of inflammation and cardiovascular disease. Application to clinical and public health practice: A statement for healthcare professionals from the Centers for Disease Control and Prevention and the American Heart Association. Circulation 2003, 107:499-511.

40. Pan A, Demark-Wahnefried W, Ye X, Yu Z, Li H, Qi Q, Sun J, Chen Y, Chen X Liu $Y$, Lin X: Effects of a flaxseed-derived lignan supplement on Creactive protein, IL- 6 and retinol-binding protein 4 in type 2 diabetic patients. Br J Nutr 2009, 101:1145-1149.

41. Dodin S, Cunnane S, Mâsse B, Lemay A, Jacques H, Asselin G, TremblayMercier J, Marc I, Lamarche B, Légaré F, Forest J: Flaxseed on cardiovascular disease markers in healthy menopausal women: a randomized, double-blind, placebo-controlled trial. Nutrition 2008 24:23-30.

42. Robertson RP: Chronic oxidative stress as a central mechanism for glucose toxicity in pancreatic islet beta cells in diabetes. $J$ Biol Chem 2004, 279(41):42351-42354

43. Furukawa S, Fujita T, Shimabukuro M, Iwaki M, Yamada Y, Nakajima Y, Nakayama O, Makishima M, Matsuda M, Shimomura I: Increased oxidative stress in obesity and its impact on metabolic syndrome. J Clin Invest 2004, 114(12):1752-1761.

44. Rudich A, Tirosh A, Potashnik R, Hemi R, Kanety H, Bashan N: Prolonged oxidative stress impairs insulin-induced GLUT4 translocation in 3T3-L1 adipocytes. Diabetes 1998, 47(10):1562-1569.

45. Estrada DE, Ewart HS, Tsakiridis T, Volchuk A, Ramlal T, Tritschler H, Klip A: Stimulation of glucose uptake by the natural coenzyme alpha-lipoic acid/thioctic acid: participation of elements of the insulin signaling pathway. Diabetes 1996, 45(12):1798-1804.

46. Rhee $Y$, Brunt A: Flaxseed lignan increased red blood cell glucose uptake. The Open Nutraceuticals J 2009, 2:81-85.

47. Prasad K: Hydroxyl radical-scavenging property of secoisolariciresinol diglucoside (SDG) isolated fromflax-seed. Mol Cell Biochem 1997, 168:117-123.

48. Hosseinian FS, Muir AD, Westcott ND, Krol ES: AAPH-mediated antioxidant reactions of secoisolariciresinol and SDG. Org Biomol Chem 2007, 5(4):644-654.

49. Houstis N, Rosen ED, Lander ES: Reactive oxygen species have a causal role in multiple forms of insulin resistance. Nature 2006, 440(7086):944-948.

50. Lin Y, Berg AH, lyengar P, Lam TK, Giacca A, Combs TP, Rajala MW, Du X, Rollman B, Li W, Hawkins M, Barzilai N, Rhodes CJ, Fantus IG, Brownlee M, Scherer PE: The hyperglycemia-induced inflammatory response in adipocytes: the role of reactive oxygen species. J Biol Chem 2005, 280(6):4617-4626.

51. Tinahones F, Murri-Pierri M, Garrido-Sánchez L, García-Almeida J, GarcíaSerrano S, García-Arnés J, García-Fuentes E: Oxidative stress in severely obese persons is greater in those with insulin resistance. Obesity 2009, 17(2):240-246

52. Shin M, Park E, Lee J, Chung N: Relationship between insulin resistance and lipid peroxidation and antioxidant vitamins in hypercholesterolemic patients. Ann Nutr Metab 2006, 50:115-120.

53. Norris SL, Zhang X, Avenell A, Gregg E, Bowman B, Schmid CH, Lau J: Long-term effectiveness of weight-loss interventions in adults with prediabetes: a review. Am J Prev Med 2005, 28:126-139.

54. Monnier L, Mas E, Ginet C, Michel F, Villon L, Cristol J, Colette C: Activation of oxidative stress by acute glucose fluctuations compared With sustained chronic hyperglycemia in patients With type 2 diabetes. JAMA 2006, 295:1681-1687.

55. Danodna P, Aljada A, Bandyopadhyay A: Inflammation: the link between insulin resistance, obesity and diabetes. Trends Immunol 2004, 25:4-7.

56. Dahl W, Lockert E, Cammer A, Whiting S: Effects of flaxseed fiber on laxation and glycemic response in healthy volunteers. J Med Food 2005, 8(4):508-511.

57. Ma Y, Griffith J, Chasan-Taber L, Olendzki B, Jackson E, Stanek E, Li W, Pagoto S, Hafner A, Ockene I: Assocation between dietary fiber and serum C-reactive protein. Am J Clin Nutr 2006, 83:760-766.

doi:10.1186/1475-2891-10-44

Cite this article as: Rhee and Brunt: Flaxseed supplementation improved insulin resistance in obese glucose intolerant people: a randomized crossover design. Nutrition Journal 2011 10:44. 